Conditio Judaica 29

Studien und Quellen zur deutsch-jüdischen Literatur- und Kulturgeschichte

Herausgegeben von Hans Otto Horch

in Verbindung mit Alfred Bodenheimer, Mark H. Gelber und Jakob Hessing 

Irving Massey

\section{Philo-Semitism in Nineteenth-Century German Literature}

Max Niemeyer Verlag Tübingen 2000 
Die Deutsche Bibliothek - CIP-Einheitsaufnahme

\section{Massey, Irving:}

Philo-semitism in nineteenth-century German literature / Irving Massey. - Tübingen: Niemeyer, 2000

(Conditio Judaica ; 29)

\section{ISBN 3-484-65129-6 ISSN 0941-5866}

(C) Max Niemeyer Verlag GmbH, Tübingen 2000

Das Werk einschließlich aller seiner Teile ist urheberrechtlich geschützt. Jede Verwertung außerhalb der engen Grenzen des Urheberrechtsgesetzes ist ohne Zustimmung des Verlages unzulässig und strafbar. Das gilt insbesondere für Vervielfältigungen, Übersetzungen, Mikroverfilmungen und die Einspeicherung und Verarbeitung in elektronischen Systemen. Printed in Germany.

Gedruckt auf alterungsbeständigem Papier.

Druck: Weihert-Druck GmbH, Darmstadt

Einband: Nädele Verlags- und Industriebuchbinderei, Nehren 